\title{
Impacts of COVID-19 on Air Quality over China: Links with Meteorological Factors and Energy Consumption
}

Special Issue:

Special Issue on COVID-19 Aerosol Drivers, Impacts and Mitigation (XVIII)

\section{OPEN ACCESS}

Received: December 26, 2020

Revised: April 4, 2021

Accepted: July 11, 2021

${ }^{*}$ Corresponding Author:

pradeep.khatri.a3@tohoku.ac.jp

\section{Publisher:}

Taiwan Association for Aerosol Research

ISSN: $1680-8584$ print

ISSN: 2071-1409 online

(c) Copyright: The Author(s).

This is an open access article distributed under the terms of the Creative Commons Attribution License (CC BY 4.0), which permits unrestricted use, distribution, and reproduction in any medium, provided the original author and source are cited.

\author{
Pradeep Khatri ${ }^{1,2^{*}}$, Tadahiro Hayasaka ${ }^{1}$ \\ ${ }^{1}$ Center for Atmospheric and Oceanic Studies, Graduate School of Science, Tohoku University, \\ Sendai, Japan \\ ${ }^{2}$ Research Institute for Humanity and Nature, Kyoto, Japan
}

\begin{abstract}
The stringent control measures in China to curb the spread of Coronavirus disease (COVID-19) have had profound societal and environmental impacts, including changes in energy consumption practices and thereby in air pollutant emissions. In this study, a suite of satellite and numerically assimilated air pollution and meteorological data combined with information on energy consumption practices and nighttime light (NTL) was used to evaluate the effects of these COVID-19 control measures on air quality. These data revealed that control measures reduced aerosols mostly over central and eastern parts of China by countering favorable meteorological conditions for increased aerosols. The control measures reduced short-lived nitrogen dioxide $\left(\mathrm{NO}_{2}\right)$ with little influence on long-lived carbon monoxide (CO). Consistent with energy production and energy consumption statistics in different sectors, NTL data suggest that high human mobility within the residential sector and reduced activity in other sectors during the implementation of control measures explain small but significant decreases in black carbon and sulfate aerosols, respectively, during this period. Overall, these results provide useful information for policy makers and the scientific community by clarifying the contributions of meteorological factors and energy consumption to changes in air quality. This information can guide the development of air pollution mitigation strategies and provides insight into the air pollution status in China and the potential for longdistance transport.
\end{abstract}

Keywords: COVID-19, Air quality, Energy consumption, Nighttime light

\section{INTRODUCTION}

A newly identified disease detected in Wuhan, China at the end of December 2019, later named coronavirus disease 2019 (COVID-19), spread rapidly in China and then worldwide over a very short time period, forcing the World Health Organization (WHO) to declare a global pandemic in March 2020. To control the spread of the virus, the central government of China implemented strong preventive measures, including full lockdowns or restrictions on social and human activities, including maintaining social distance, preventing large gatherings, and controlling the use of public transportation. The COVID-19 pandemic is ongoing, and several countries have taken (or are still taking) preventive measures similar to those in China to curb the spread. Despite the global health crisis, huge economic losses, and several social inconveniences, COVID-19 control measures have unintentionally had some beneficial effects. For example, the improvement in air quality due to the COVID-19 control measures may have substantially reduced non-COVID-19 deaths and diseases related to air pollution (Chen et al., 2020).

Targeting certain societal events, short-term pollution reduction experiments conducted in the past, including "Olympic Blue" for the 2008 Beijing Summer Olympic Games (Wang et al., 2010) and "APEC Blue" for the 2014 Asia-Pacific Economic Cooperation (APEC) Economic Leaders' 
meeting (Huang et al., 2015), have shown the potential to reduce air pollution by up to $60 \%$. COVID-19 control measures curbed human activities at a broader scale. This provides a valuable opportunity to understand the general links between human activities and air quality degradation, with significant implications for policy making, climate change studies, and so on. Accordingly, relevant studies have increased exponentially since the COVID-19 outbreak. The majority of studies have focused on quantifying pollution reduction due to control measures in different parts of the world, providing insight into the contribution of human engagement to air quality degradation in different regions. Because control measures to prevent the spread of COVID-19 affect several aspects of society, including human mobility, energy consumption, and lifestyle, it is important to understand the effects of behavioral changes on air quality by analyzing these factors collectively. Furthermore, meteorological factors are key determinants of air quality (e.g., Tie et al., 2017; Liang et al., 2019) and must be considered when estimating the precise contribution of human activities to air quality degradation.

In this study, to characterize atmospheric changes in response to measures to prevent COVID-19, we focused on a wide area in China extending east-west from Shanghai to Sichuan and northsouth from Beijing to Guangzhou. The study area was carefully chosen for the following reasons. First, it includes most cities placed under control by the Chinese government (He et al., 2020), and the epicenter of COVID-19 (i.e., Wuhan city) is roughly in the center. Second, it includes several areas with high energy consumption and high population density (Dong et al., 2018). Third, air pollution emitted from this region can transport over long distances (Khatri et al., 2010, 2014), providing an opportunity to understand the characteristics of such long-range transported air pollutants in the source region.

\section{DATA}

\subsection{Aerosols}

Aerosol optical depth (AOD) at $0.55 \mu \mathrm{m}$ was obtained from the Moderate Resolution Imaging Spectroradiometer (MODIS) sensor aboard Terra and Aqua satellites as well as Modern-Era Retrospective Analysis Research and Applications, Version 2 (MERRA-2). MODIS Collection 6.1 land products at a 3-km resolution (Levy et al., 2013; Remer et al., 2013) (i.e., MOD04_3K for Terra and MYD04_3K for Aqua) were used. AOD data corresponding to local observation times of around 10:30:00 and 13:30:00 from MODIS sensors aboard Terra and Aqua satellites, respectively, are cloud screened and thus are available only for clear sky days. MERRA-2 is an atmospheric reanalysis produced by NASA Global Modeling and Assimilation Office (GMAO), aimed at providing data for global atmosphere and surface properties at fixed spatial and temporal resolutions (Gelaro et al., 2017). MERRA-2 has a wide range of products, including surface characteristics, atmospheric constituents, and meteorological parameters, as described in detail by Gelaro et al. (2017). We used MERRA-2 AOD (Randels et al., 2017) assimilated with Goddard Earth Observing System-5 (GEOS-5) coupled with the Goddard Chemistry Aerosol Radiation and Transport (GOCART) model (Chin et al., 2002) and aerosol observations from different platforms (MODIS, Multiangle Imaging SpectroRadiometer [MISR], Aerosol Robotic Network [AERONET], and Advanced very-high-resolution radiometer [AVHRR]). MERRA-2 AOD has a spatial resolution of $0.5^{\circ}$ (latitude) $\times 0.625^{\circ}$ (longitude) and a temporal resolution of $1 \mathrm{~h}$.

\subsection{Column Concentrations of Nitrogen Dioxide $\left(\mathrm{NO}_{2}\right)$ and Carbon Monoxide (CO)}

Column concentrations of nitrogen dioxide $\left(\mathrm{NO}_{2}\right)$ and carbon monoxide $(\mathrm{CO})$ over the study region were obtained from TROPOspheric Monitoring Instrument (TROPOMI) aboard the Copernicus Sentinel-5 Precursor satellite S5P (Veefkind et al., 2012), which has an overpass time of around 13:30:00 (local time) and repeat cycle of 17 days. The spatial resolution of the TROPOMI product was $3.5 \times 7.0 \mathrm{~km}^{2}$ up to 5 August, 2019 and is now available at $3.5 \times 5.5 \mathrm{~km}^{2}$. The details of $\mathrm{NO}_{2}$ and $\mathrm{CO}$ retrieval processes are described by van Geffen et al. (2020) and Landgraf et al. (2016), respectively. We used only data with quality control values greater than 0.75 . We used Level 2 products. 


\subsection{Nighttime Light (NTL)}

The Day/Night Band (NDB) sensor of Visible Infrared Imaging Radiometer Suite (VIIRS) aboard Suomi National Polar-orbiting Partnership (S-NPP) and Joint Polar Satellite System (JPSS) satellite platforms provides measurements of nocturnal visible and near infra-red light (Roman et al., 2018). VIIRS DNB provides monitoring data for both the magnitude and signature of nighttime and anthropogenic sources of light emissions. Realizing the importance of VIRRS DNB time series records in earth system sciences, NASA has developed the Black Marble product suite (VNP46) to generate nighttime light (NTL) data. The NTL data used in this study are VNP46A1 with a spatial resolution of $500 \mathrm{~m}$. NTL data were used to extract information related to human activity. Previous studies (e.g., Li et al., 2018; Hasan et al., 2019) have shown that NTL has different threshold values for different light sources. It has been suggested that NTL of $5-20 \mathrm{nW} \mathrm{cm}^{-2} \mathrm{sr}^{-1}$, 20-40 nW cm$~^{-2} \mathrm{sr}^{-1}$, and $>40 \mathrm{nW} \mathrm{cm}^{-2} \mathrm{sr}^{-1}$ are representative values for residential areas, transportation and public facilities, and commercial centers, respectively (Ma, 2018). Furthermore, NTL less than $5 \mathrm{nW} \mathrm{cm}^{-2} \mathrm{sr}^{-1}$ results from water, snow, and vegetation (Ma, 2018). Thus, for quality control, pixels with NTL $<5 \mathrm{nW} \mathrm{cm}^{-2} \mathrm{sr}^{-1}$ were excluded after screening cloud-affected pixels.

\subsection{Energy Consumption}

We used electricity and coal consumption data for China provided by the China Energy Portal (https://chinaenergyportal.org/en/2020-q2-electricity-other-energy-statistics/). Fundamental data related to energy production and consumption, including total power production, power consumption, and coal consumption for heat supply, are provided quarterly (three months of a year) for the last few years. Energy data for 2020 were compared with those for previous years to understand changes in energy consumption practices and human mobility.

\subsection{Meteorological Data}

Meteorological data were obtained from MERRA-2. Similar to aerosol data described above, they were assimilated with GEOS-5. Among a number of meteorological parameters, precipitable water content (PWC), air temperature at $2 \mathrm{~m}$ from the surface, and planetary boundary layer top pressure data were used. Data are available every $3 \mathrm{~h}$ with the same spatial resolution for aerosol.

\section{STUDY AREA}

The study area is shown in Fig. 1 along with altitudes above sea level and the population

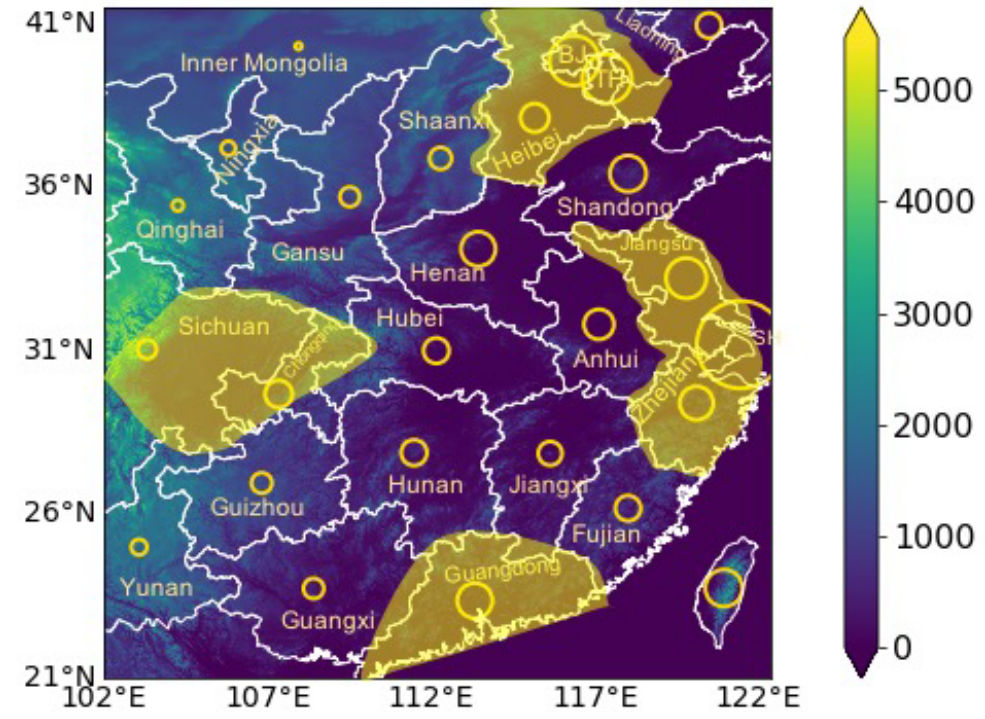

$$
\begin{array}{cc}
\begin{array}{c}
\text { Population } \\
\text { density } \\
\left(\# / \mathrm{km}^{2}\right)
\end{array} \\
0 & 300 \\
\mathrm{O} & 600 \\
\bigcirc & 900 \\
\bigcirc & 1200 \\
\bigcirc & 1500 \\
\bigcirc & 1800
\end{array}
$$

Fig. 1. Topography and population density in each province in the study area. Shaded areas show major population and economic sectors (upper: Beijing-Tianjin-Hebei [BTH], right: Yangtze River Delta [YRD], lower: Pearl River Delta [PRD], left: Sichuan Basin [SCB]). 
density (individuals per $\mathrm{km}^{2}$ ) of each province. The study area shows topological variation and regions with different atmospheric backgrounds. The population density is generally high in the east and decreases gradually towards the west. The three major population and economic sectors of China fall in the study area: the Yangtze River Delta (YRD), located on the eastern coast comprising Shanghai, Jiangsu Province, and Zhejiang Province; the Pearl River Delta (PRD), which includes Guangdong Province, in the south; and the Beijing-Tianjin-Hefei (BTH) region in the north. The study area also includes mostly rural provinces (e.g., Yunnan, Guangxi, and Guizhou), which are influenced by the biomass burning activities of neighboring countries to the southwest (Huang et al., 2019). The Sichuan Basin (SCB) is populated by more than 100 million people with more than 11 million vehicles (Li et al., 2021), with mountains of about 1000-3000 m altitude around it. Such high mountains can limit the transport of air pollution out of the valley. The northwest provinces of China are roughly in the upper left corner of our study area (Qinghai, Gansu, Ningxia, Inner Mongolia, and Shaanxi) and are, in general, downwind of Asian deserts (e.g., the Gobi Desert and Taklamakan Desert). Accompanying rapid economic growth, recent air pollution in and around central China (e.g., Hubei, Henan, Hunan) is severe (e.g., Wang et al., 2014; 2015). Based on the locality and atmospheric background, we divided the study area into the following seven sectors: Sector 1 (PRD, Jiangsu, Fujian, Anhui), Sector 2 (BTH, Shandong), Sector 3 (Qinghai, Gansu, Ningxia, Inner Mongolia, and Shaanxi), Sector 4 (Sichuan, Chongqing), Sector 5 (Hubei, Henan, Hunan), Sector 6 (Yunnan, Guangxi, Guizhou), and Sector 7 (Guangdong).

\section{STUDY METHODS}

The central government of China implemented stringent traffic restrictions and quarantine measures, first in Wuhan and then in other cities of Hubei province on 23 January 2020 (daynumber for 2020 [DNY] 23). These measures were then extended to other parts of China 2 days later. After a rapid decrease in COVID-19 cases, the Chinese government relaxed the control level in most parts of China, expect in Hubei province, by 14 March 2020 (DNY 74). Finally, the restrictions were ended in Hubei province, including Wuhan, on 4 April 2020 (DNY 95). The timeline is shown in Fig. 2. We analyzed data for the first 4 months (January to April) of 2019 and 2020, focusing on understanding changes in atmospheric constituents in response to restrictions on human mobility and human activities to prevent COVID-19. The spring festival was held on 25 January to 2 February in 2020 and on 4-10 February in 2019. Excluding spring festivals (when air pollution is generally reduced, potentially impacting our analysis), we divided the study period into three groups, Normal, Lockdown, and New Normal defined as 1-21 January (DNY 1-21), 10 February to 14 March (DNY 39-71), and 15 March to 30 April (DNY 72-120) of 2020, as shown in Fig. 2. Although control measures were implemented only in 2020 , for simplicity, DNY 1-21, DNY

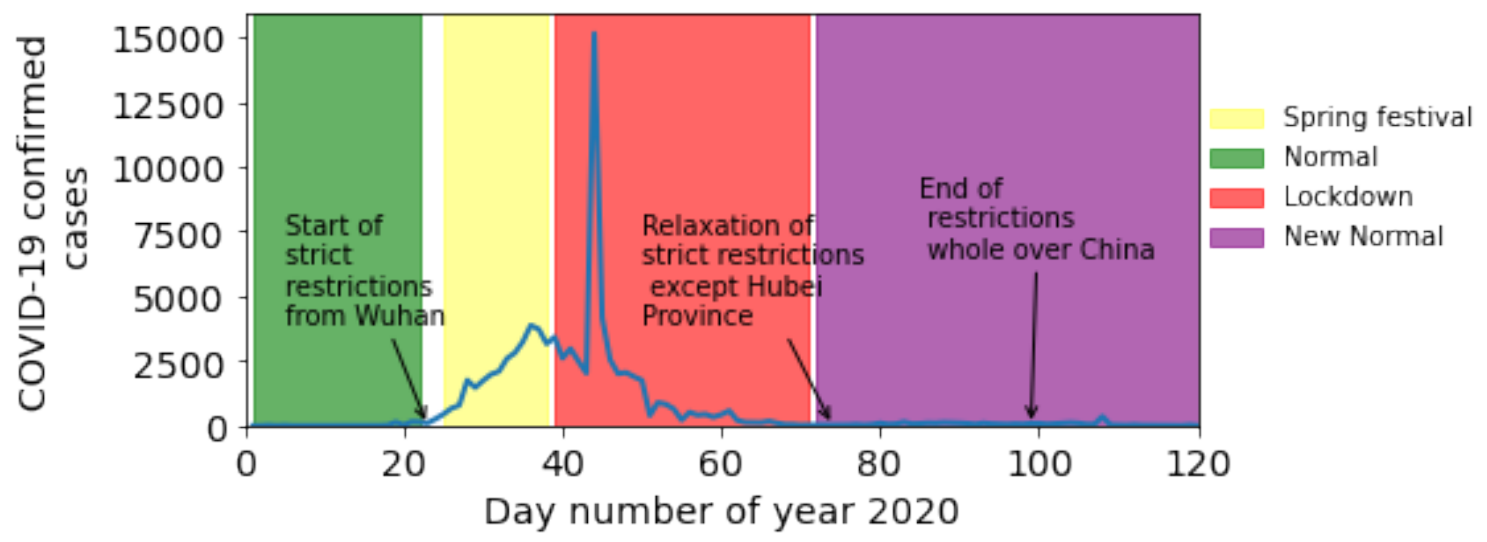

Fig. 2. Time series of confirmed COVID-19 cases within China when control measures were in place. Shaded areas show spring festival holidays (4 February-10 February in 2019; 25 January-2 February in 2020) and Normal, Lockdown, and New Normal periods defined in this study. The confirmed COVID-19 cases are total numbers of new confirmed cases each day in China (source: https://github.com/owid). 
39-71, and DNY 72-120 of 2019 are also termed Normal, Lockdown and New Normal, respectively. To quantify the impacts of control measures on concentrations of trace gases and aerosols, we estimated mean values over the study area for each study period and year. The changes in pollution concentrations during the Lockdown period of 2020 with respect to the values in the previous year were analyzed by accounting for changes during the pre- and post-Lockdown periods as well. These air pollution data were then coupled with changes in energy production and consumption practices within China as well as NTL data obtained from space to understand human mobility and activity in different sectors.

\section{RESULTS}

\subsection{Spatial Distribution of Aerosol Optical Depth (AOD)}

Fig. 3 shows the spatial distribution of AOD at $0.55 \mu \mathrm{m}$ from MODIS (Terra + Aqua) for the Normal, Lockdown, and New Normal periods of 2020 and 2019. MODIS data alone are insufficient to clearly understand the spatiotemporal variation in AOD over the study region owing to missing data (shown in white in Fig. 3). Therefore, we further show mean MERRA-2 AOD for each period in both 2019 and 2020 in Fig. 4. Note that MODIS AODs are only daytime observations of clear sky days, whereas MERRA-2 AODs are hourly data for both day and night for all sky conditions. These differences in temporal resolution can explain differences in spatial distribution patterns between Figs. 3 and 4. Some studies (e.g., Penna et al., 2018; Aldabash et al., 2020) have shown that MODIS and MERRA-2 AODs are consistent in terms of temporal variation; however, MODIS AODs can be higher than MERRA-2 values. The study sectors described in Section 2 were further divided into highly populated ( $>1$ million) and moderately or less populated ( $<1$ million) regions to calculate their mean AODs (Table 1). The population data are available from PopulationStat (https://populationstat.com). Sector 1 (highly urbanized eastern China), Sector 4 (SCB), and Sector 5 (central China) had higher aerosol loadings than other sectors during all periods. On the other hand, in Sector 3 (semi-arid region), there was low aerosol loading during all periods, suggesting that Asian dust aerosols had little effect on the study area during the study period. Table 1 suggests no clear relationship between population and AOD in highly urbanized sectors (Sectors 1, 2, and 7) and the semi-arid sector (Sector 3). On the other hand, AOD values were
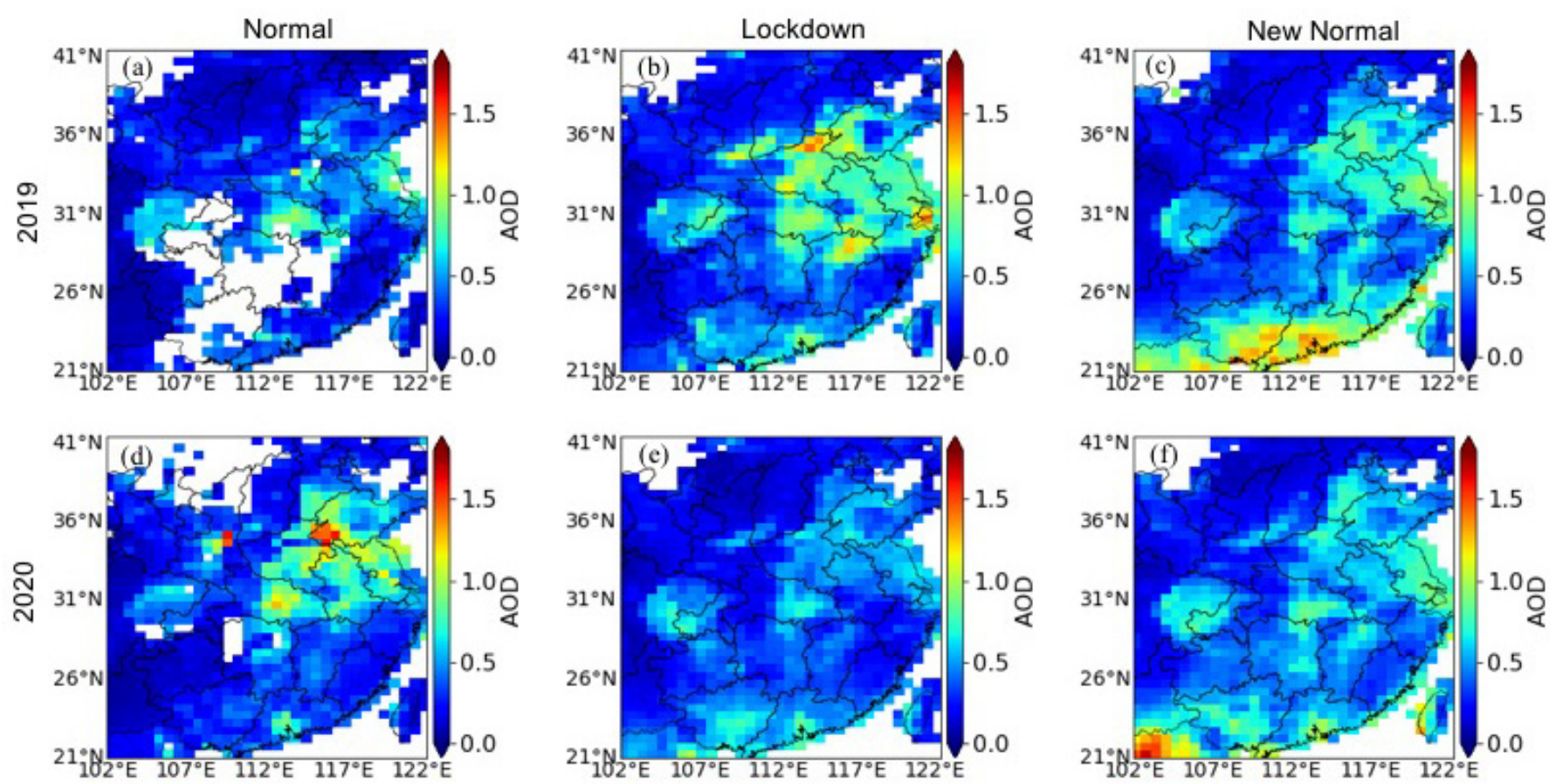

Fig. 3. Mean values of MODIS (Terra+Aqua) observed AODs at $0.55 \mu \mathrm{m}$ during days corresponding to Normal (left), Lockdown (middle), and New Normal (right) periods in 2019 (a-c) and 2020 (d-e). 

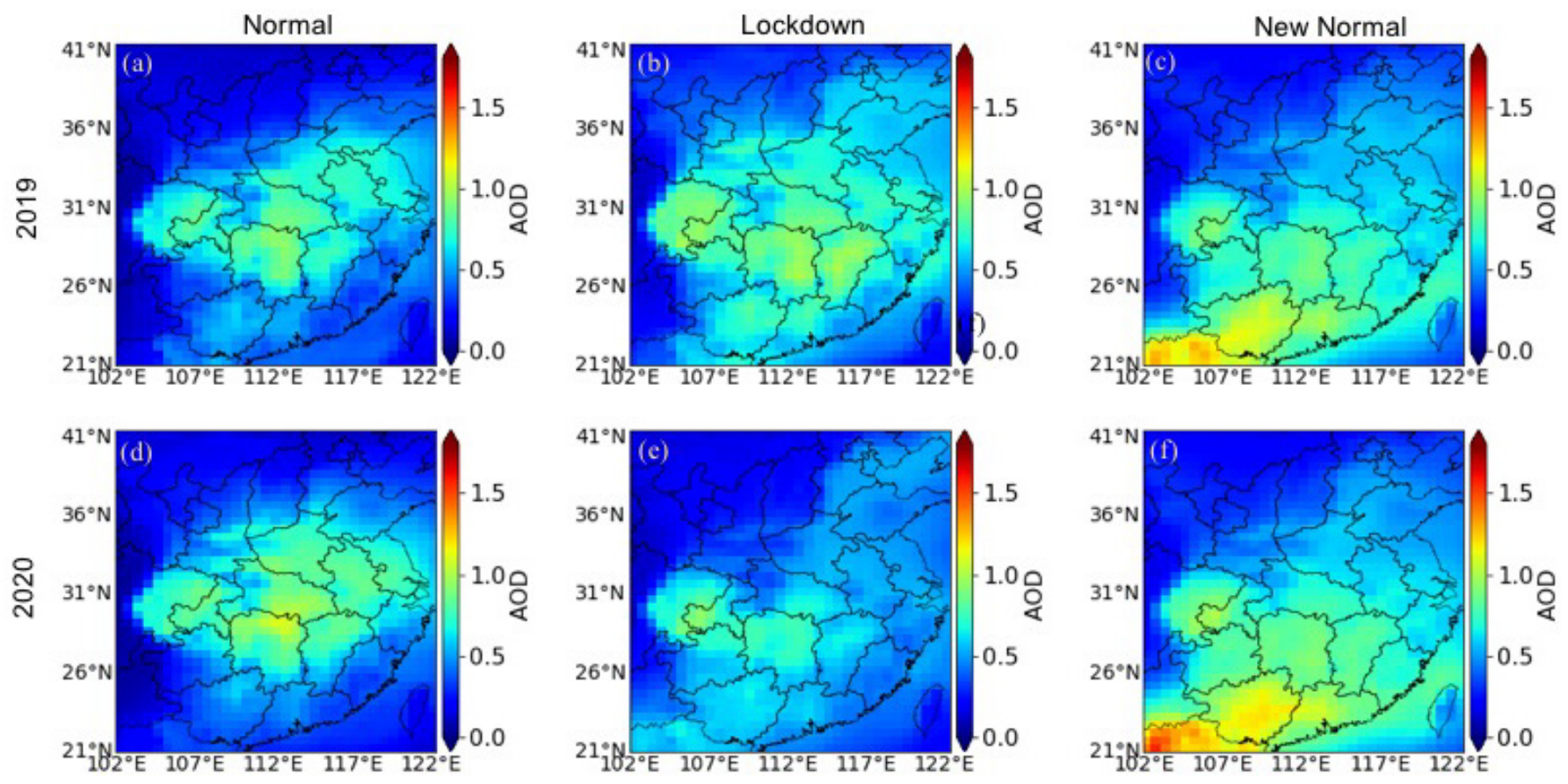

Fig. 4. Daily AODs (24-h mean values) at $0.55 \mu \mathrm{m}$ from MERRA-2.

Table 1. Mean AOD values for regions with population greater than 1 million and less than 1 million for different sectors.

\begin{tabular}{|c|c|c|c|c|c|c|c|c|c|c|c|c|}
\hline \multirow{3}{*}{ Sector ${ }^{a}$} & \multicolumn{6}{|c|}{2019} & \multicolumn{6}{|c|}{2020} \\
\hline & \multicolumn{2}{|c|}{ Normal } & \multicolumn{2}{|c|}{ Lockdown } & \multicolumn{2}{|c|}{ New Normal } & \multicolumn{2}{|c|}{ Normal } & \multicolumn{2}{|c|}{ Lockdown } & \multicolumn{2}{|c|}{ New Normal } \\
\hline & $>1$ mil. & $<1$ mil. & $>1$ mil. & $<1$ mil. & $>1 \mathrm{mil}$. & $<1$ mil. & $>1$ mil. & $<1$ mil. & $>1$ mil. & $<1$ mil. & $>1$ mil. & $<1$ mil. \\
\hline 1 & 0.61 & 0.59 & 0.69 & 0.7 & 0.64 & 0.65 & 0.67 & 0.66 & 0.52 & 0.52 & 0.64 & 0.68 \\
\hline 2 & 0.39 & 0.39 & 0.56 & 0.56 & 0.48 & 0.49 & 0.4 & 0.4 & 0.47 & 0.47 & 0.46 & 0.48 \\
\hline 3 & 0.27 & 0.29 & 0.47 & 0.53 & 0.35 & 0.36 & 0.36 & 0.42 & 0.27 & 0.28 & 0.35 & 0.37 \\
\hline 4 & 0.69 & 0.63 & 0.87 & 0.76 & 0.71 & 0.67 & 0.73 & 0.66 & 0.71 & 0.65 & 0.8 & 0.75 \\
\hline 5 & 0.73 & 0.71 & 0.79 & 0.77 & 0.67 & 0.66 & 0.84 & 0.81 & 0.58 & 0.58 & 0.7 & 0.7 \\
\hline 6 & 0.49 & 0.38 & 0.64 & 0.52 & 0.83 & 0.75 & 0.46 & 0.33 & 0.58 & 0.49 & 0.9 & 0.84 \\
\hline 7 & 0.43 & 0.45 & 0.6 & 0.63 & 0.82 & 0.83 & 0.4 & 0.41 & 0.51 & 0.52 & 0.94 & 0.94 \\
\hline
\end{tabular}

a Sector 1: Shanghai municipality, Jiangsu province, Zhejiang province, Fujian province, Jiangxi province, and Anhui province. Sector 2: Hebei province, Beijing municipality, Tianjin municipality, and Shandong province.

Sector 3: Shaanxi province, Gansu province, Qinghai province, and Inner Mongolia autonomous region.

Sector 4: Sichuan province, Chongqing province.

Sector 5: Hubei province, Henan province, and Hunan province.

Sector 6: Yunnan province, Guizhou province, Guangxi province.

Sector 7: Guangdong province.

remarkably different between highly populated and moderately or less populated regions in relatively less urbanized sectors (Sectors 4, 5, and 6). The Normal period in 2020 was characterized by higher aerosol loading than that in the same period of 2019. The mean MODIS (MERRA-2) AOD values were $0.28 \pm 0.19(0.4 \pm 0.22)$ in 2019 and $0.37 \pm 0.25(0.43 \pm 0.24)$ in 2020 for this period. The high AOD in 2020 can be explained by meteorological conditions, discussed in detail in Section 6.1. Furthermore, Fig. 4 reveals that dense aerosol loading is confined mainly to $26^{\circ} \mathrm{N}-$ $36^{\circ} \mathrm{N}$, which includes mainly Sectors 1,4 , and 5 , during this period. This belt includes not only a high population, but also major coal-fired power stations, including Beilun, Jianxi, Ninghai, Waigaoqiao, Yuhuan, and Jianbi. However, AOD was far lower during the Lockdown period than in the Normal period in 2020, as shown in both Figs. 3 and 4. The decrease in AOD over a large part of the study area can be detected in comparison with AODs for the same period of 2019. AODs during the Lockdown period of 2020 decreased mainly over the eastern and central parts 
of China. The decrease of AOD was nearly same for highly populated and moderately or less populated regions. In particular, Shanghai, Jiangsu province, Zhejiang province, Anhui province, Fujian province, Jiangxi province, Hubei province, Henan province, and Shaanxi province showed drastic reductions in AOD (see upper panel of Fig. 9). In fact, considerably high rates of COVID-19 infections were recorded over those cities and provinces (https://en.wikipedia.org/wiki/COVID19_pandemic_in_mainland_China), and they were under stringent control measures to curb the spread of the disease (He et al., 2020). Despite similar stringent control measures, some regions, including Beijing and southern Yunnan province, had higher AOD in 2020 than in 2019 during the Lockdown period (see the upper panel of Fig. 9). It is plausible that the high AODs over the northern region reflect meteorological conditions, as discussed in detail in Section 6.1, and those over the southern region were due to biomass burnings in neighboring southwest countries, as stated in Section 3. The mean MODIS (MERRA-2) AOD values were $0.43 \pm 0.25(0.54 \pm 0.21)$ in 2019 and $0.34 \pm 0.17(0.43 \pm 0.17)$ in 2020 for this period. As shown in Figs. 3 and 4, all regions with decreased aerosol loading during the Lockdown period showed increases during the New Normal period following the termination of control measures. The mean MODIS (MERRA-2) AOD values were $0.47 \pm 0.28(0.55 \pm 0.24)$ in 2019 and $0.44 \pm 0.24(0.59 \pm 0.27)$ in 2020 for the New Normal period.

Reductions in human mobility and human activities to curb COVID-19 are expected to impact primarily anthropogenic air pollutants. We evaluated the effects of control measures on different pollution types related to human activity. Fig. 5 shows the spatial distribution of MERRA-2 sulfate AOD at $0.55 \mu \mathrm{m}$ for the three periods in 2020 and 2019. Li et al. (2017) suggested that emissions from industries and power plants can result in about $60 \%$ and $30 \%$ of total sulfate aerosols in China, respectively, suggesting that the change in sulfate AOD is an important indicator of the effects in industrial and power sectors. Sulfate AOD within the $26^{\circ} \mathrm{N}-36^{\circ} \mathrm{N}$ belt, which includes mainly Sectors 1, 4, and 5, was elevated during the Normal period in both 2019 and 2020. Like total AOD, sulfate AOD was higher in 2020 than in 2019 over the whole study area during the Normal period. Overall, the mean sulfate AOD values were $0.29 \pm 0.19$ and $0.32 \pm 0.21$ in 2019 and 2020, respectively, during this period. Despite the increased sulfate aerosol loading before the start of control measures, it was significantly lower during the Lockdown period of 2020. With respect to the same period in 2019, sulfate AOD during the Lockdown period of 2020 decreased over the regions that showed a decrease in total AOD in Fig. 4, suggesting that a decrease in sulfate aerosol contributed substantially to the total AOD decrease during the Lockdown period.
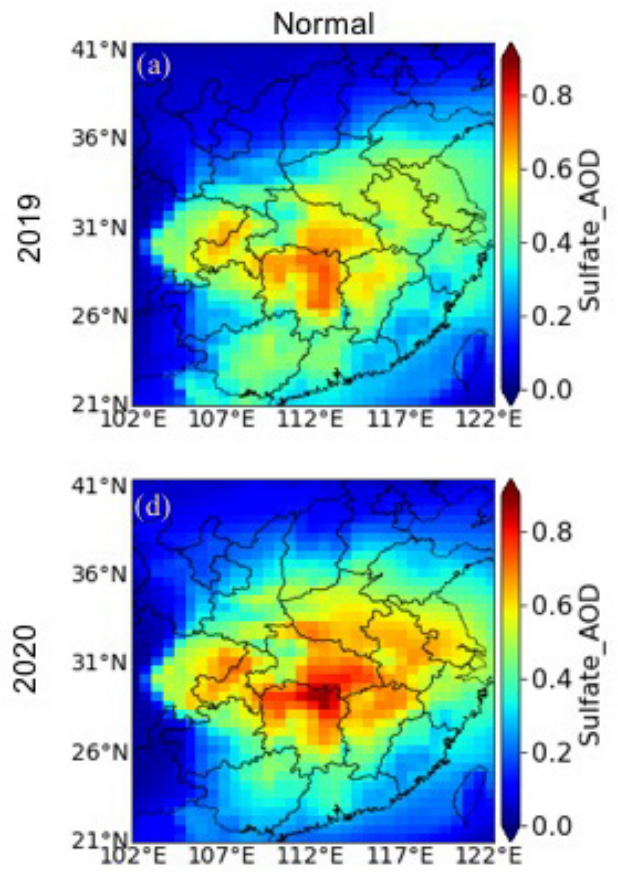
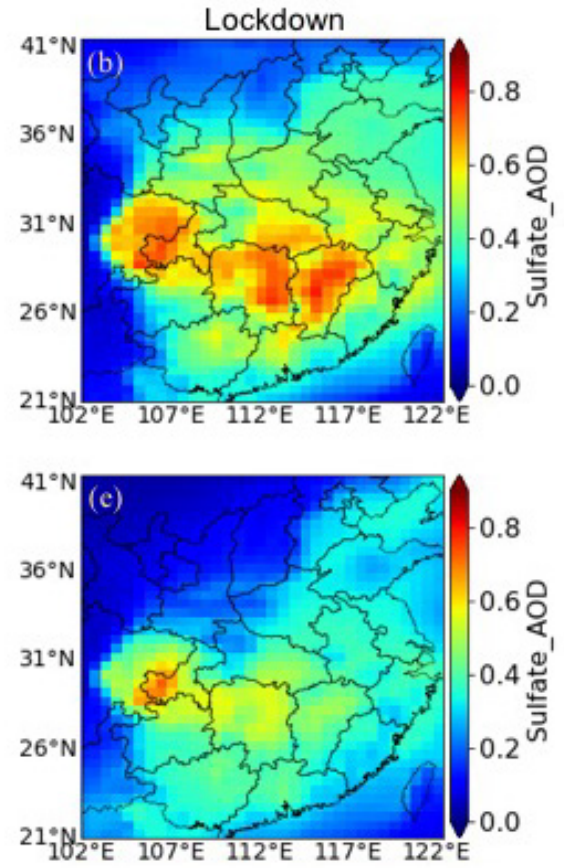
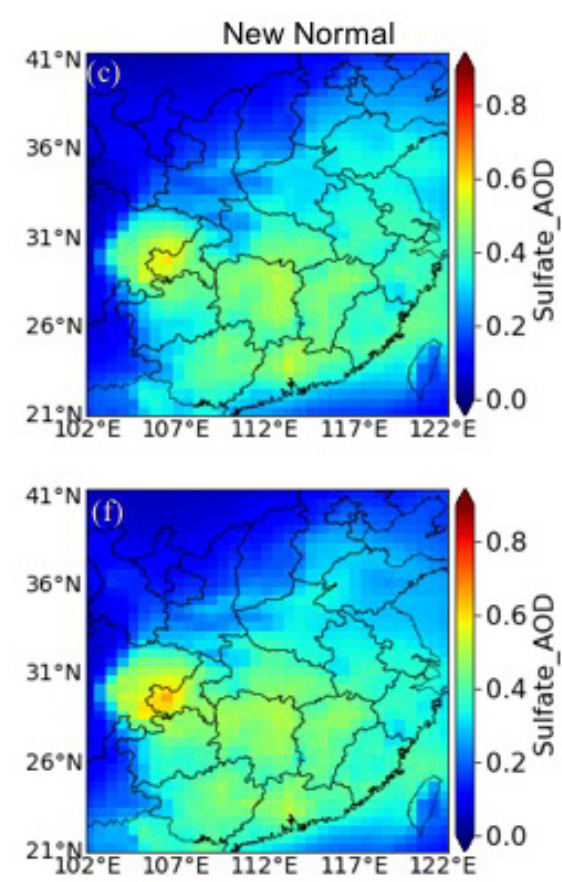

Fig. 5. Daily sulfate AODs (24-h mean values) at $0.55 \mu \mathrm{m}$ from MERRA-2. 
Thus, the stringent control measures to curb COVID-19 had substantial effects on industrial and power sectors. Overall, sulfate AOD decreased from a mean value of $0.37 \pm 0.17$ in 2019 to $0.28 \pm$ 0.14 in 2020. Similar to total AOD discussed above, sulfate AOD increased again during the New Normal period, again emphasizing that $\mathrm{SO}_{2}$ emission was reduced during the Lockdown period. The mean values of sulfate AOD during the New Normal period of 2019 and 2020 were $0.27 \pm$ 0.13 and $0.28 \pm 0.13$, respectively. Similar to Table 1 , Table 2 shows mean values of sulfate AOD for highly and moderately or less populated regions of different sectors. In general, the variations in sulfate AOD for different sectors and population regions are consistent with those shown in Table 1 and described above.

Next, we analyzed the spatial distribution of BC AOD, as shown in Fig. 6. Li et al. (2017) suggested residential and transportation sectors are the dominant sources of $\mathrm{BC}$ aerosol in China, contributing about $50 \%$ and $30 \%$, respectively. The high concentrations of $\mathrm{BC}$ aerosols prevailed primarily over Sector 2 (northeast China), Sector 4 (SCB), and Sector 5 (central China) in the Normal period of both 2019 and 2020. The air temperature was lower in the north than in the south, leading to increased BC AOD in Sector 2. Sectors 4 and 5 have considerable rural populations. The low efficiency of combustion technology, excess coal burning within the household sector, and burning of agriculture waste products can explain the high BC aerosol emissions in rural China (Zhang et al., 2018). In general, BC AOD was higher in 2019 than in 2020 during this period over nearly the whole study area. The mean BC AOD values during this period were $0.035 \pm 0.023$ and $0.032 \pm$ 0.019 in 2019 and 2020, respectively. BC aerosol has high seasonal variation, reaching a maximum in the winter due to the increased use of fossil fuel for domestic heating and stagnant meteorological conditions. Its concentration is the lowest during summer (e.g., Zhou et al., 2018). Thus, the lower BC AOD in the Lockdown period of 2020 than in the Normal period of the same year may not reflect the effect of control measures. In general, BC AODs for the Lockdown period of 2020 were comparable to those for the same period of 2019, in contrast to the sharp decrease in sulfate AOD over a wide area during the Lockdown period. The mean BC AOD values during the Lockdown period of 2019 and 2020 were $0.035 \pm 0.016$ and $0.031 \pm 0.014$, respectively. Despite a significant reduction in transportation during this period in 2020 (Zhou, 2020), active emissions by the residential sector can explain the relatively low decrease of BC aerosols. BC AOD values were generally lower during the New Normal period than during the Normal and Lockdown periods over study area, except over southwest China around Yunnan province, in both 2019 and 2020 due to increased temperature and thereby reduced fuel consumption for residential heating.
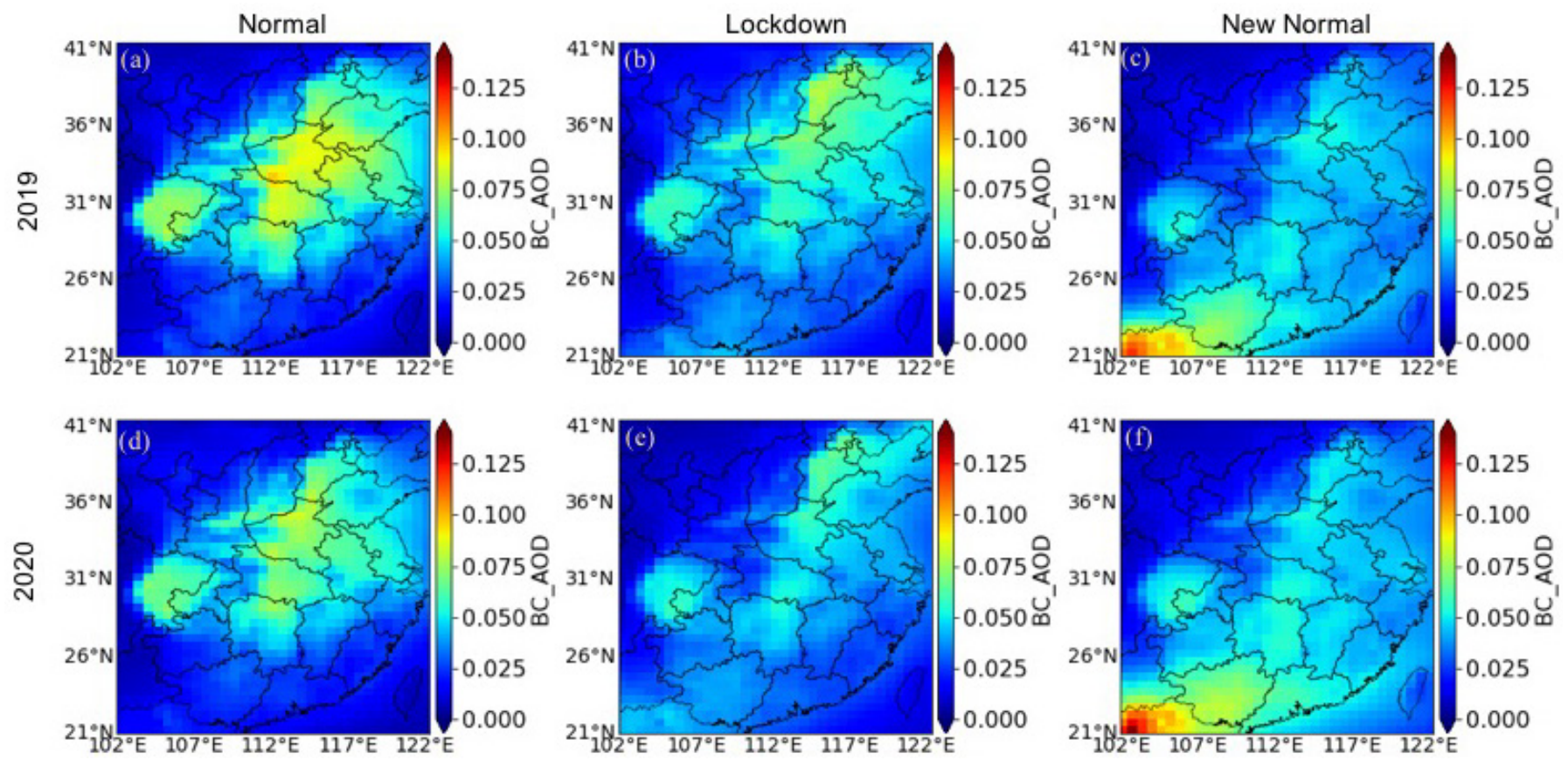

Fig. 6. Daily black carbon AODs (24-h mean values) at $0.55 \mu \mathrm{m}$ from MERRA-2. 
Table 2. Mean sulfate AOD values for regions with population greater than 1 million and less than 1 million for different sectors.

\begin{tabular}{|c|c|c|c|c|c|c|c|c|c|c|c|c|}
\hline \multirow{3}{*}{ Sector ${ }^{\mathrm{a}}$} & \multicolumn{6}{|l|}{2019} & \multicolumn{6}{|l|}{2020} \\
\hline & \multicolumn{2}{|l|}{ Normal } & \multicolumn{2}{|c|}{ Lockdown } & \multicolumn{2}{|c|}{ New Normal } & \multicolumn{2}{|l|}{ Normal } & \multicolumn{2}{|c|}{ Lockdown } & \multicolumn{2}{|c|}{ New Normal } \\
\hline & $>1$ mil. & $<1$ mil. & $>1$ mil. & $<1$ mil. & $>1$ mil. & $<1$ mil. & $>1$ mil. & $<1$ mil. & $>1$ mil. & $<1$ mil. & $>1$ mil. & $<1$ mil. \\
\hline 1 & 0.46 & 0.45 & 0.51 & 0.51 & 0.38 & 0.38 & 0.52 & 0.52 & 0.37 & 0.37 & 0.35 & 0.37 \\
\hline 2 & 0.24 & 0.25 & 0.37 & 0.38 & 0.28 & 0.28 & 0.26 & 0.27 & 0.3 & 0.3 & 0.25 & 0.26 \\
\hline 3 & 0.17 & 0.18 & 0.32 & 0.36 & 0.17 & 0.17 & 0.25 & 0.3 & 0.14 & 0.14 & 0.17 & 0.18 \\
\hline 4 & 0.51 & 0.46 & 0.66 & 0.57 & 0.44 & 0.41 & 0.56 & 0.5 & 0.51 & 0.46 & 0.5 & 0.46 \\
\hline 5 & 0.54 & 0.52 & 0.58 & 0.56 & 0.39 & 0.38 & 0.65 & 0.62 & 0.39 & 0.4 & 0.4 & 0.39 \\
\hline 6 & 0.4 & 0.3 & 0.44 & 0.33 & 0.37 & 0.3 & 0.35 & 0.24 & 0.39 & 0.31 & 0.39 & 0.33 \\
\hline 7 & 0.36 & 0.37 & 0.4 & 0.42 & 0.38 & 0.39 & 0.31 & 0.31 & 0.34 & 0.35 & 0.43 & 0.42 \\
\hline
\end{tabular}

${ }^{a}$ Sector 1: Shanghai municipality, Jiangsu province, Zhejiang province, Fujian province, Jiangxi province, and Anhui province.

Sector 2: Hebei province, Beijing municipality, Tianjin municipality, and Shandong province.

Sector 3: Shaanxi province, Gansu province, Qinghai province, and Inner Mongolia autonomous region.

Sector 4: Sichuan province, Chongqing province.

Sector 5: Hubei province, Henan province, and Hunan province.

Sector 6: Yunnan province, Guizhou province, Guangxi province.

Sector 7: Guangdong province.

Table 3. Mean BC AOD values for regions with population greater than 1 million and less than 1 million for different sectors.

\begin{tabular}{|c|c|c|c|c|c|c|c|c|c|c|c|c|}
\hline \multirow{3}{*}{ Sector ${ }^{a}$} & \multicolumn{6}{|c|}{2019} & \multicolumn{6}{|c|}{2020} \\
\hline & \multicolumn{2}{|c|}{ Normal } & \multicolumn{2}{|c|}{ Lockdown } & \multicolumn{2}{|c|}{ New Normal } & \multicolumn{2}{|c|}{ Normal } & \multicolumn{2}{|c|}{ Lockdown } & \multicolumn{2}{|c|}{ New Normal } \\
\hline & $>1 \mathrm{mil}$. & $<1$ mil. & $>1$ mil. & $<1$ mil. & $>1 \mathrm{mil}$. & $<1$ mil. & $>1 \mathrm{mil}$. & $<1$ mil. & $>1 \mathrm{mil}$. & $<1$ mil. & $>1$ mil. & $<1$ mil. \\
\hline 1 & 0.05 & 0.05 & 0.04 & 0.04 & 0.04 & 0.04 & 0.05 & 0.04 & 0.04 & 0.04 & 0.04 & 0.04 \\
\hline 2 & 0.06 & 0.05 & 0.06 & 0.06 & 0.04 & 0.04 & 0.05 & 0.05 & 0.05 & 0.05 & 0.04 & 0.04 \\
\hline 3 & 0.03 & 0.03 & 0.03 & 0.03 & 0.02 & 0.02 & 0.03 & 0.03 & 0.02 & 0.02 & 0.02 & 0.02 \\
\hline 4 & 0.07 & 0.06 & 0.05 & 0.05 & 0.04 & 0.04 & 0.06 & 0.06 & 0.05 & 0.04 & 0.05 & 0.05 \\
\hline 5 & 0.08 & 0.07 & 0.06 & 0.06 & 0.05 & 0.05 & 0.07 & 0.06 & 0.05 & 0.05 & 0.05 & 0.05 \\
\hline 6 & 0.03 & 0.02 & 0.03 & 0.03 & 0.05 & 0.05 & 0.03 & 0.02 & 0.03 & 0.03 & 0.05 & 0.05 \\
\hline 7 & 0.02 & 0.02 & 0.03 & 0.03 & 0.05 & 0.05 & 0.02 & 0.02 & 0.03 & 0.03 & 0.06 & 0.06 \\
\hline
\end{tabular}

${ }^{a}$ Sector 1: Shanghai municipality, Jiangsu province, Zhejiang province, Fujian province, Jiangxi province, and Anhui province. Sector 2: Hebei province, Beijing municipality, Tianjin municipality, and Shandong province.

Sector 3: Shaanxi province, Gansu province, Qinghai province, and Inner Mongolia autonomous region.

Sector 4: Sichuan province, Chongqing province.

Sector 5: Hubei province, Henan province, and Hunan province.

Sector 6: Yunnan province, Guizhou province, Guangxi province.

Sector 7: Guangdong province.

The considerably high BC AOD around Yunnan province coincided with high total AODs, as shown in Figs. 3 and 4. The mean BC AOD values were $0.035 \pm 0.018$ and $0.038 \pm 0.019$ in 2019 and 2020, respectively, during the New Normal period. Further, Table 3 shows the mean BC AOD values for highly and moderately or less populated regions of different sectors. Although BC AOD values were not remarkably different between highly populated and moderately or less populated regions in Table 3, some Sectors show relatively larger BC AOD values in highly populated region compared with moderately or less populated region, suggesting that population was one factor in increased BC AOD.

\subsection{Spatial Distribution of Trace Gases $\left(\mathrm{NO}_{2}\right.$ and $\left.\mathrm{CO}\right)$}

Fig. 7 shows the spatial distribution of columnar $\mathrm{NO}_{2}$ for different study periods of 2020 and 2019. A high $\mathrm{NO}_{2}$ concentration was detected over highly urbanized areas, including Beijing, Shanghai, Tianjin, Hangzhou, and Guangzhou. $\mathrm{NO}_{2}$ is produced from the combustion of fuels, including hydrocarbons, especially at high temperatures such as in car engines (Omidvarborna et al., 2015). The lifetime of $\mathrm{NO}_{2}$ is just a few hours (Liu et al., 2016), constraining its spread from 

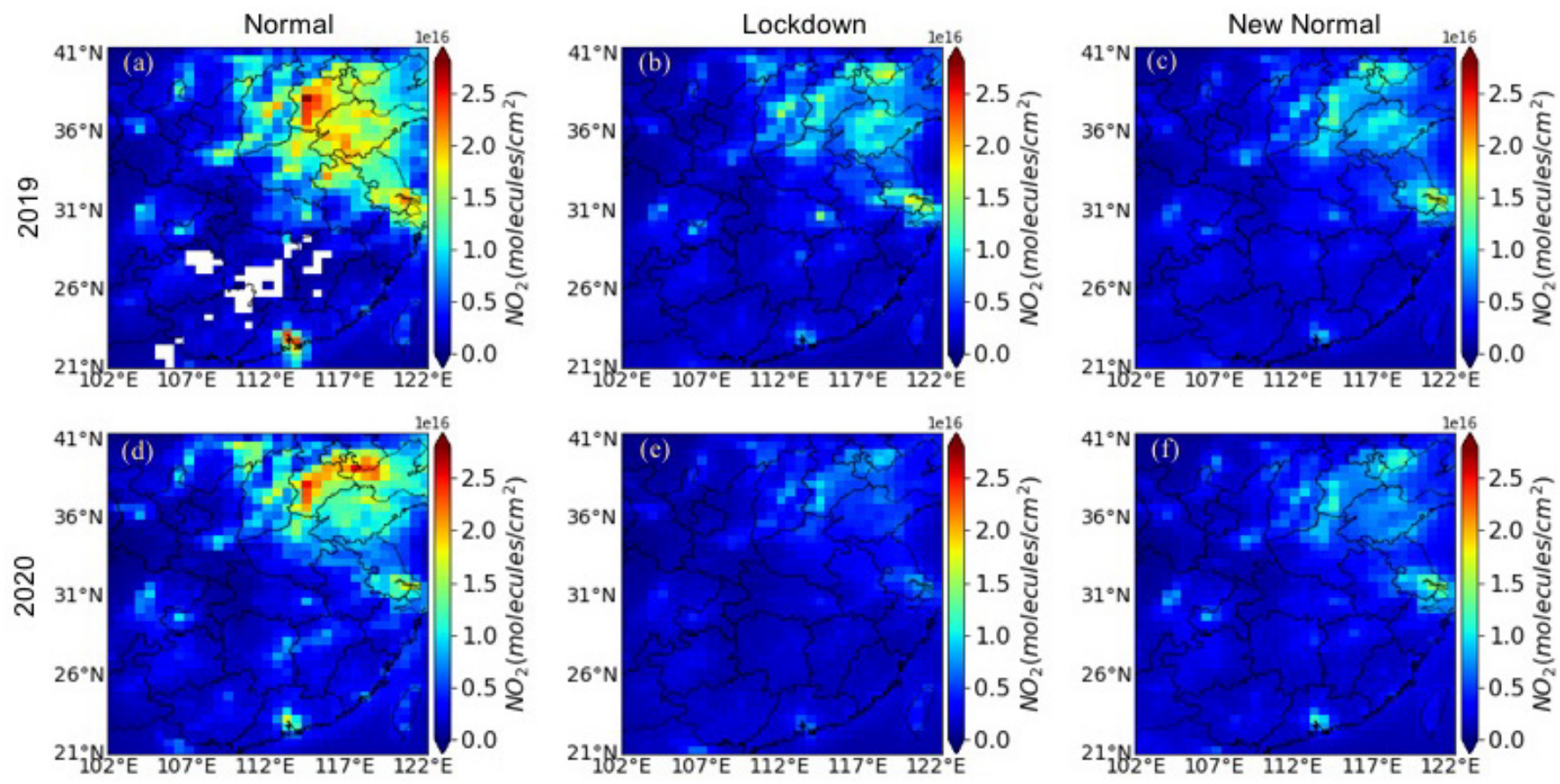

Fig. 7. $\mathrm{NO}_{2}$ from TROPOMI.

the source regions. The $\mathrm{NO}_{2}$ concentration during the Normal period of 2020 was lower than that during the same period of 2019. The mean values were $5.20 \pm 5.27 \times 10^{15}$ and $4.22 \pm 4.20 \times$ $10^{15}$ molec. $\mathrm{cm}^{-2}$ for 2019 and 2020, respectively, during this period. The low $\mathrm{NO}_{2}$ in 2020 can be attributed to new environmental regulations for air pollution implemented in China (Duncan et al., 2016). Although laws and regulations for air pollution mitigation have been modified and improved over a long time period (Yan, 2020), the most stringent action plan to date was established in 2013 (Zhang et al., 2019). The COVID-19 control measures further decreased $\mathrm{NO}_{2}$ concentrations over these urban areas during the Lockdown period of 2020, resulting in the mean values of $3.11 \pm 2.76 \times 10^{15}$ and $2.22 \pm 1.52 \times 10^{15}$ molec. $\mathrm{cm}^{-2}$ in 2019 and 2020, respectively. This approximately $30 \%$ reduction in $\mathrm{NO}_{2}$ was larger than the $\mathrm{AOD}$ reduction of around $20 \%$, reflecting the shorter atmospheric residence time of $\mathrm{NO}_{2}$ than of aerosols. The remarkable reduction of $\mathrm{NO}_{2}$ during the Lockdown period can be suggested to be primarily due to a reduction in transportation (Zhou, 2020). However, the $\mathrm{NO}_{2}$ concentration was higher in the New Normal period of 2020 than in the Lockdown period of the same year, presumably due to resumption of transportation. Of note, the concertation of $\mathrm{NO}_{2}$ was still lower during the New Normal period of 2020 than in the same period of 2019 as a result of new environmental regulations for pollution reduction, as stated above. Quantitatively, $\mathrm{NO}_{2}$ concentrations during the New Normal period were $3.13 \pm 2.41 \times 10^{15}$ and $2.90 \pm 2.13 \times 10^{15}$ molec. $\mathrm{cm}^{-2}$ in 2019 and 2020 , respectively. It is important to note the low contribution of biomass burning in neighboring southwestern countries to the increase in $\mathrm{NO}_{2}$ over southwest China, which can be explained mainly by the distant source regions and short lifetime of $\mathrm{NO}_{2}$.

Fig. 8 shows the spatial distribution of columnar $\mathrm{CO}$, which is produced by the incomplete combustion of carbon-based fuels and atmospheric oxidization of hydrocarbon. Industrial and transportation sectors are important sources of $\mathrm{CO}$ in developed eastern and north-central China; residential combustion is an important source in less developed territories of China (Zhao et al., 2012). Similar to $\mathrm{NO}_{2}$ discussed above, the $\mathrm{CO}$ concentration shows a linear decrease over time in East Asia, including China (Zheng et al., 2018) due to improved energy efficiency and/or energy control regulation. Zheng et al. (2018) detected an accelerated decline in CO emissions after 2013. This is consistent with our results indicating lower concentrations of CO over developed eastern and north-central China during the Normal period in 2020 than in 2019, with mean values of $2.94 \pm 0.95 \times 10^{17}$ and $2.88 \pm 0.79 \times 10^{17}$ molec. $\mathrm{cm}^{-2}$, respectively. To some extent, the COVID-19 control measures may have reduced CO concentrations during the Lockdown period of 2020 

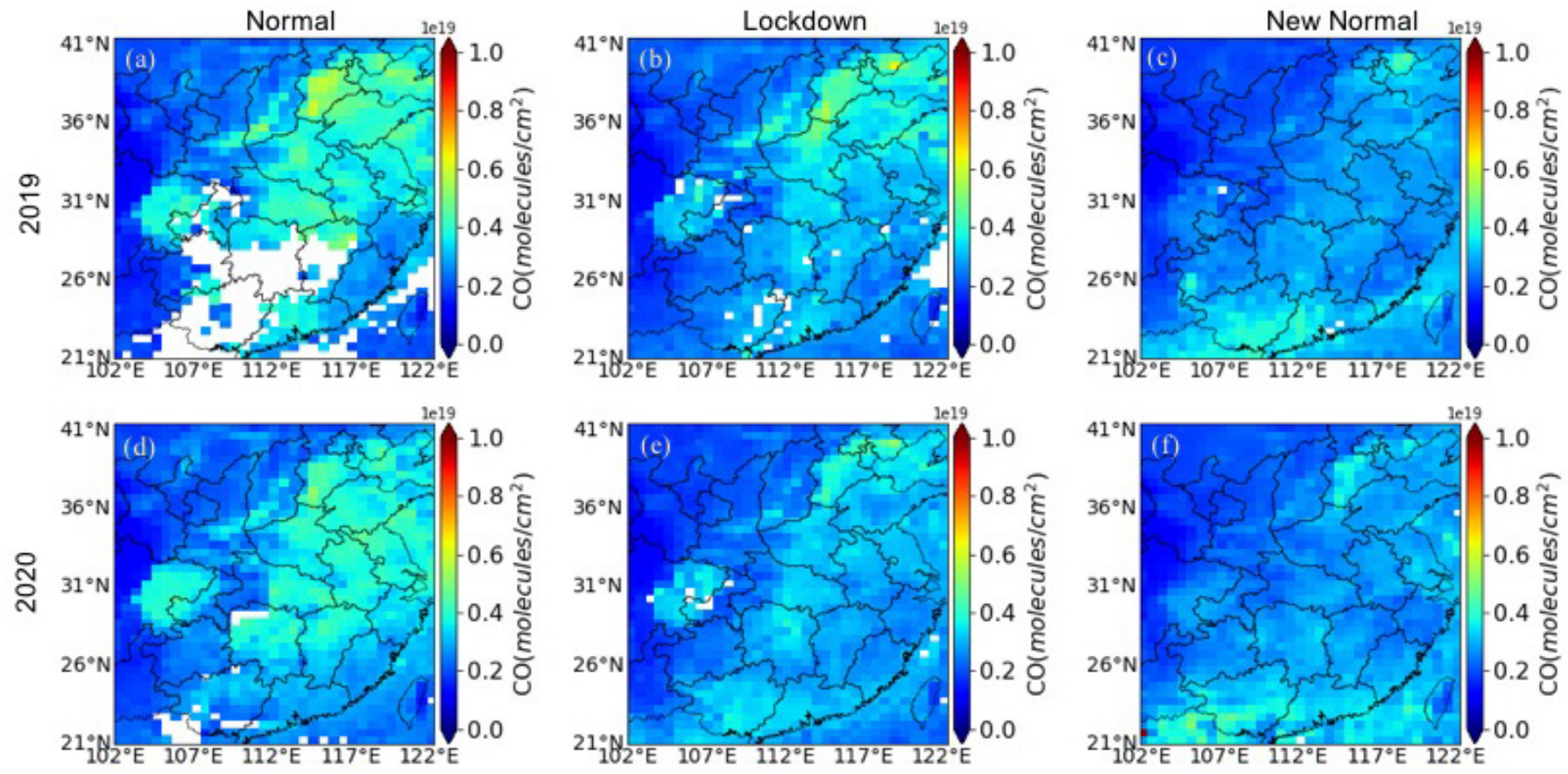

Fig. 8. CO from TROPOMI.

compared with those in the same period of 2019, particularly over highly developed cities such as Beijing, Tianjin, Shanghai, and Guangzhou. However, the reduction in CO was not as prominent as the reduction in $\mathrm{NO}_{2}$ due to the longer residence time of $\mathrm{CO}$, estimated to range from 0.3 to 5.0 years (Jaffe, 1968). The mean values of CO were $2.76 \pm 0.73 \times 10^{17}$ and $2.66 \pm 0.62 \times$ $10^{17}$ molec. $\mathrm{cm}^{-2}$ during this period in 2019 and 2020, respectively. Furthermore, there was not a remarkable difference in the $\mathrm{CO}$ concentration between the Lockdown and New Normal periods of 2020 or between the New Normal periods of 2020 and 2019. The mean CO values for the New Normal period were $2.58 \pm 0.58 \times 10^{17}$ and $2.67 \pm 0.66 \times 10^{17}$ molec. $\mathrm{cm}^{-2}$ in 2019 and 2020 , respectively. It is also important to note the high concentrations of CO over southwestern China around Yunnan province in both 2019 and 2020 during the New Normal period.

\section{DISCUSSION}

This section discusses the links between air pollution over our study region and meteorological factors, energy consumption practices, and human mobility, with the aim of better understanding the effectiveness of control measures to curb COVID-19 for pollution reduction.

\subsection{Meteorology}

Figs. 9(a-c) shows the AOD difference between 2020 and 2019 for the Normal, Lockdown, and New Normal periods. In general, AODs were higher in 2020 than in 2019 during the Normal and New Normal periods; however, the opposite pattern was observed in some locations during the Lockdown period. Here, we discuss the importance of meteorological factors in determining the increase in AOD over some regions during the Lockdown period by countering control measures that tended to reduce pollution.

Figs. 9(d-f) shows PWC differences between 2020 and 2019 for different study periods. The water vapor in the atmosphere was higher in 2020 than that in 2019 for all study periods. Water vapor in the atmosphere can increase AOD by increasing the aerosol size (Khatri and Ishizaka, 2007). Additionally, an increased aerosol size can lead to more rapid multiphase reactions and secondary aerosol formation (Liang et al., 2019), thereby increasing the aerosol number concentration (Tie et al., 2017). Thus, the high PWC in 2020 compared with 2019 was more favorable to increase aerosol loading in the atmosphere. 

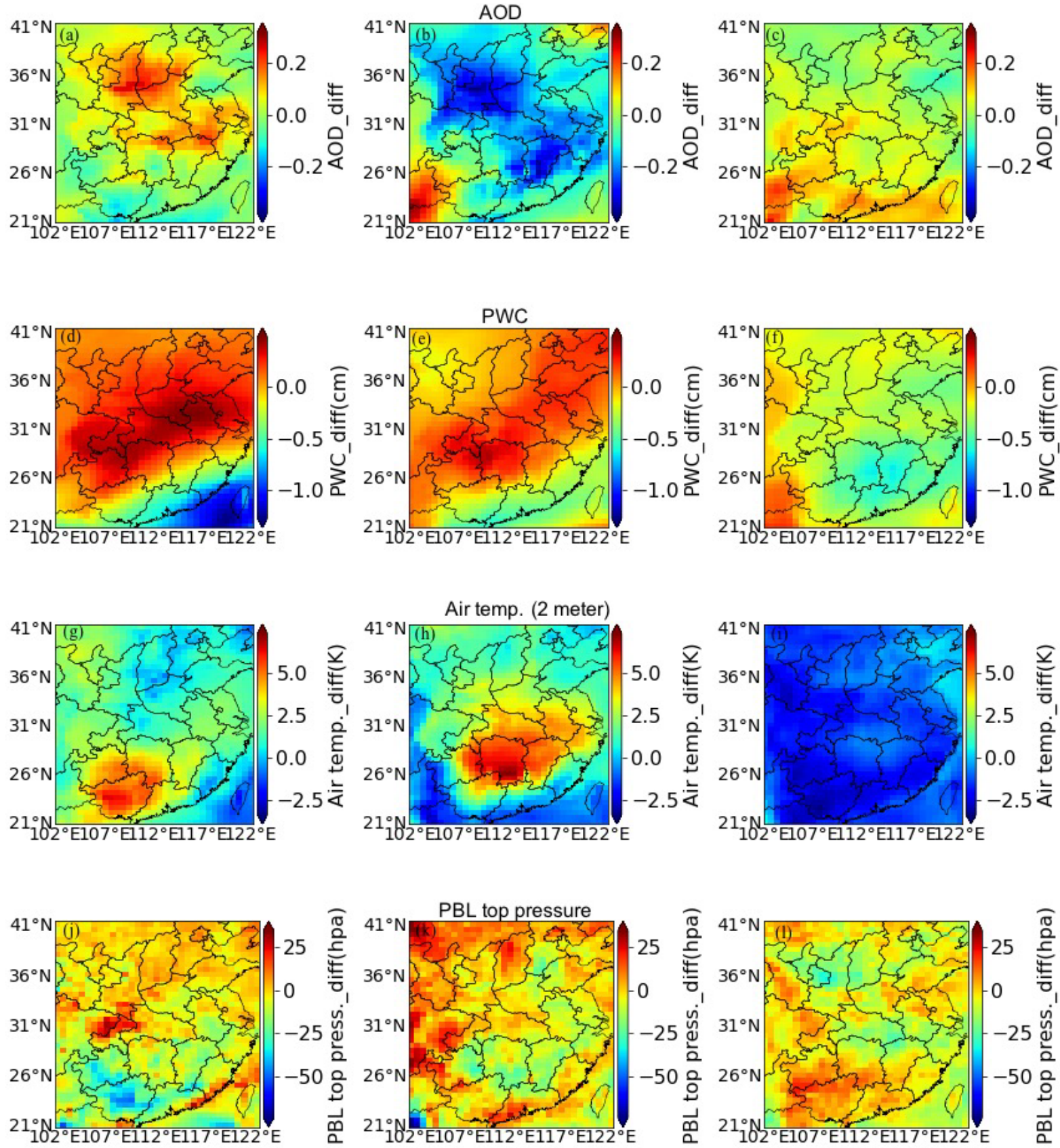

Fig. 9. Difference between 2020 and 2019 for (a-c) AOD at $0.55 \mu \mathrm{m}$ (upper), (d-f) PWC, (g-i) air temperature at an altitude of $2 \mathrm{~m}$ and $(\mathrm{j}-\mathrm{l})$ planetary boundary layer top pressure. The left, middle, and right panels correspond to Normal, Lockdown, and New Normal periods, respectively. A positive difference indicates a higher value for 2020 than for 2019.

Figs. 9(g-i) shows differences in air temperature at an altitude of $2 \mathrm{~m}$ between 2020 and 2019 for different study periods. Broadly, AOD and air temperature showed a negative relationship in each study period. In other words, a positive AOD difference (indicating a higher value in 2020) was detected over regions with a negative air temperature difference and vice versa. This relationship was particularly strong during the Lockdown period. A decreased temperature can increase energy consumption for heating, thereby increasing air pollution. As noted above, the Lockdown period of 2020 was characterized by a slight BC aerosol reduction, suggesting that there was not a remarkable difference in incomplete combustion activities between the Lockdown period of 2020 and the same period of 2019. Although the generation of clean energy is increasing, coal and biomass burning are still largely used for household heating and cooking purposes in China (Xiao et al., 2015). 
Finally, Figs. $9(j-1)$ shows the difference in the planetary boundary layer top pressure between 2020 and 2019 for different study periods. The height of the boundary layer was smaller in 2020 than in 2019. This decrease can increase aerosol loading by two pathways. First, it can increase the relative humidity, aerosol, and ozone concentration near the surface (Zhu et al., 2018), creating favorable conditions for the heterogenous chemistry of aerosols (Liang et al., 2019). Second, it can further stabilize the lower atmosphere by the radiative effect (Wang et al., 2013) and suppress precipitation by microphysical processes (Wang et al., 2016).

Overall, the meteorological conditions in 2020 were more favorable than those in 2019 for high aerosol loading in the atmosphere. This can explain the higher AODs in 2020 than in 2019 during the Normal and New Normal periods. However, the stringent control measures during the Lockdown period countered such favorable meteorological conditions. As a result, AODs increased over regions where meteorological factors could dominate stringent control measures during the Lockdown period of 2020.

\subsection{Energy Consumption}

Control measures to curb the spread of COVID-19 had several societal impacts, including a change in energy consumption practices. Despite expansion of clean energy production, China is the largest producer and consumer of coal in the world and is the largest user of coal-derived electricity (https://en.wikipedia.org/wiki/Coal_in_China). Fig. 10 shows annual variation in total energy consumption and production as well as in coal combustion for heating. Such data for the whole country are made public on a quarterly basis. Power consumption and production have increased rapidly within the last few years. Data corresponding to the first quarter of the year (Q1, i.e., January to March) can help us to understand the effect of COVID-19 control measures on the energy sector. Industrial power consumption and total power generation in 2020 decreased during Q1, although power consumption in the residential sector and total coal combustion for heating increased steadily, as in previous years, in 2020 during Q1. This suggests that COVID-19 control measures had substantial effects on the industrial and power sectors, without influencing the residential sector. Furthermore, coal burning for heating increased steadily in 2020, as in previous years. These data provide science-based evidence that coal burning activities within the household sector were the primary source of air pollution during the Lockdown period. Interestingly,
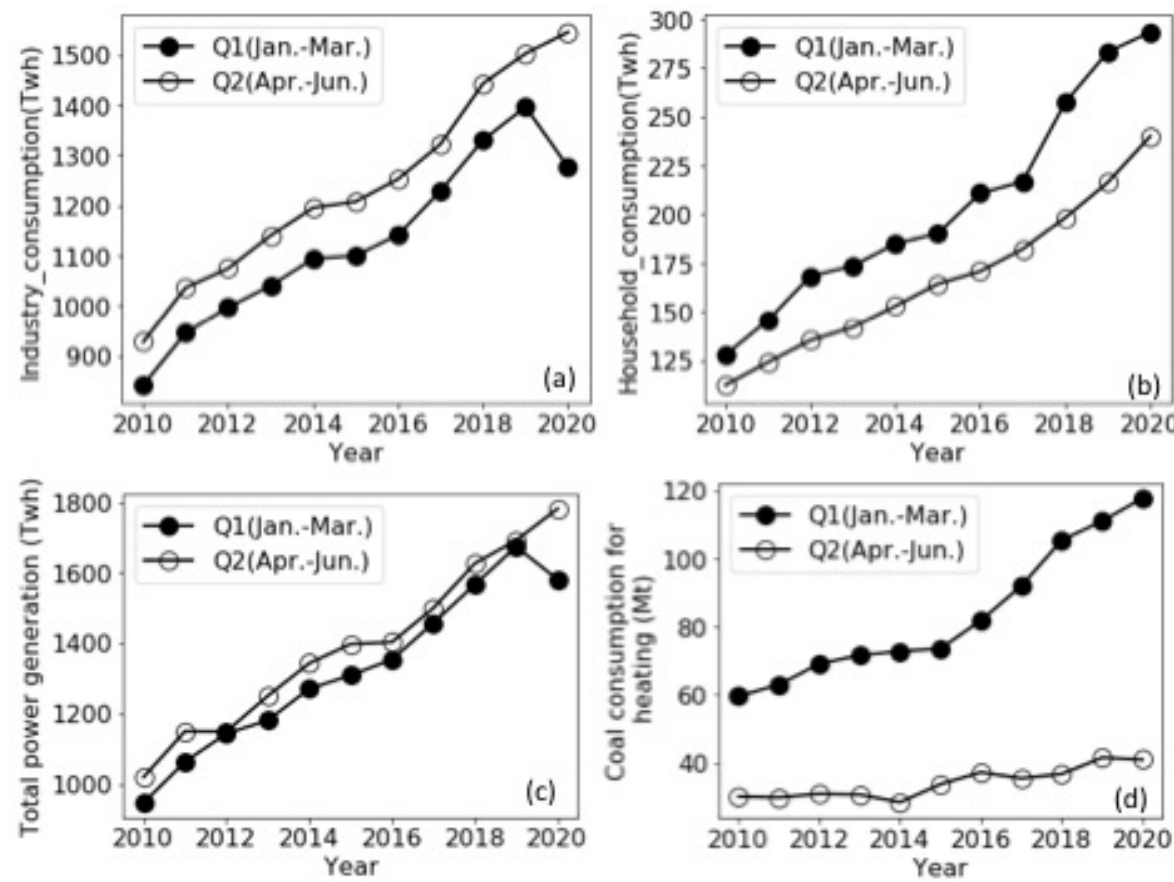

Fig. 10. Yearly variation in (a) total electricity consumption by industry, (b) total electricity consumption by households, (c) total electric power production, and (d) total coal consumption for heating in China for January-March (Q1) and April-June (Q2). 
data corresponding to the second quarter (Q2, i.e., April to June) suggest that the industrial and power sectors resumed activities after the end of COVID-19 control measures. Furthermore, coal consumption was significantly elevated in China during the cold months. Overall, Fig. 10 provides strong evidence to suggest that emissions from industrial and power sectors decreased during the Lockdown period, explaining the drastic reduction in sulfate aerosols but not BC aerosols during this period in 2020 .

\subsection{Human Mobility and Activity}

Table 4 shows the percentages of total pixels corresponding to $5<\mathrm{NTL} \leq 20 \mathrm{nW} \mathrm{cm} \mathrm{sr}^{-1}, 20$ $<\mathrm{NTL} \leq 40 \mathrm{nW} \mathrm{cm} \mathrm{sr}^{-1}$, and NTL $>40 \mathrm{nW} \mathrm{cm}^{-2} \mathrm{sr}^{-1}$ values for the Normal, Lockdown, and New Normal periods of 2019 and 2020. Pixels with NTL $<5 \mathrm{nW} \mathrm{cm} \mathrm{sr}^{-1}$ were discarded because they represent vegetation, water, or snow (Ma, 2018). Pixels with $5<\mathrm{NLT} \leq 20 \mathrm{nW} \mathrm{cm} \mathrm{sr}^{-1}$, corresponding to residential areas, were more frequent in 2019 than in 2020 during the Normal period. In 2020 (2019), the pixel frequency for residential areas during the Lockdown period was higher (lower) than that during the Normal period. In 2020, pixels with $20<\mathrm{NTL} \leq 40 \mathrm{nW} \mathrm{cm} \mathrm{cr}^{-1}$ decreased gradually from the Normal to New Normal periods; whereas pixels with $5<\mathrm{NLT} \leq 20 \mathrm{nW} \mathrm{cm}^{-2} \mathrm{sr}^{-1}$ increased gradually. Table 1 further shows that pixels with NTL $>40 \mathrm{nW} \mathrm{cm}^{-2} \mathrm{sr}^{-1}$ were the lowest (highest) during the Lockdown period of 2020 (2019) among all study periods. Overall, coinciding with other results, these data provide additional evidence for the increased (decreased) human mobility and activity in the residential (commercial and transportation) sector during the period of COVID-19 control measures in 2020, explaining the slight reduction in BC aerosol, despite substantial decreases in sulfate aerosol and $\mathrm{NO}_{2}$ during the Lockdown period of 2020. Thus, NTL data provide new insight into the link between human mobility and activity and air pollution.

\section{CONCLUSIONS}

This study aimed to clarify the links between air quality and meteorological factors, energy consumption practices, and human mobility in China during, before, and after the periods of stringent control measures implemented from 23 January 2020 until 14 March 2020 across nearly one-third of the country to curb the spread of COVID-19. We used satellite and reanalysis data along with energy statistics made public by the Chinese government. We detected higher aerosol loading in 2020 than in 2019 before the spread of COVID-19 and further found that the stringent control measures reduced aerosol loading only over certain regions, mainly in the central and eastern parts of China, with a rebound after the central government relaxed the control measures. We found that meteorological conditions in 2020 were more favorable than those in 2019 for increased aerosol loading, suggesting that regional variation in changes in aerosol loading during the period of stringent control measures could be explained by the balance between meteorological factors and man-made emission control. In general, the $\mathrm{NO}_{2}$ concentration in 2020 was lower than that in 2019 before the initiation of stringent control measures, although the control measures further reduced the concentration in the atmosphere. Similar to aerosols, $\mathrm{NO}_{2}$ levels rebounded after the relaxation of control measures. Long-lived CO was only slightly affected by control measures. Energy consumption by the industrial sector and total power production were noted to decrease, without any effect on residential energy consumption and coal combustion

Table 4. Percentages of total pixels in the study region with different ranges of nighttime light (NTL).

\begin{tabular}{lllll}
\hline $\begin{array}{l}\text { Ranges of } \mathrm{NTL} \\
\left(\text { unit: } \mathrm{nW} \mathrm{cm} \mathrm{cm}^{-2} \mathrm{sr}^{-1}\right)\end{array}$ & Year & \multicolumn{3}{c}{ Period } \\
\cline { 3 - 5 } $5<\mathrm{NLT} \leq 20$ & 2019 & Normal & Lockdown & New Normal \\
& 2020 & $74.08 \%$ & $77.85 \%$ & $82.11 \%$ \\
$20<\mathrm{NLT} \leq 40$ & 2019 & $16.2 \%$ & $77.47 \%$ & $87.15 \%$ \\
& 2020 & $21.74 \%$ & $18.68 \%$ & $16.56 \%$ \\
$\mathrm{NLT}>40$ & 2019 & $1.72 \%$ & $20.91 \%$ & $10.98 \%$ \\
& 2020 & $4.03 \%$ & $3.47 \%$ & $1.32 \%$ \\
\hline
\end{tabular}


for heating purposes during the first quarter of 2020, and rebounded to the levels observed in previous years during the second quarter of 2020, indicating higher (lower) human mobility in the residential (industrial and power) sector during the periods of control measures. These patterns of human mobility during, before, and after the periods of stringent control measures were supported by an analysis of satellite-observed NTL. These findings further explain the drastic reduction in sulfate aerosols without a significant $\mathrm{BC}$ aerosol reduction during the period of stringent control measures, providing a science-based evidence for the weak and strong effects of control measures on pollution reductions in the residential and industrial sectors. Overall, these results have implications for policy makers and the scientific community by providing insight into the impact of similar control measures on pollution emitted from different sectors.

\section{ACKNOWLEDGMENTS}

This study is supported by a Grant-in-Aid for Scientific Research (C) 17 K05650 from the Japan Society for the Promotion of Science (JSPS), the "Virtual Laboratory for Diagnosing the Earth's Climate System" program of MEXT, Japan, and Research Institute for Humanity and Nature (RIHN: a constituent member of NIHU) Project No. 14200133 (Aakash).

\section{DISCLAIMER}

The authors have no conflict of interest.

\section{REFERENCES}

Aldabash, M., Bektas Balcik, F., Glantz, P. (2020). Validation of MODIS C6.1 and MERRA-2 AOD using AERONET observations: A comparative study over Turkey. Atmosphere 11, 905. https://doi.org/10.3390/atmos11090905

Chen, K., Wang, M., Huang, C., Kinney, P.L., Anastas, P.T. (2020). Air pollution reduction and mortality benefit during the COVID-19 outbreak in China. Lancet Planet. Heath 4, e210-e212. https://doi.org/10.1016/s2542-5196(20)30107-8

Chin, M., Gioux, P., Kinne, S., Torres, O., Holben, B.N., Duncan, B.N., Martin, R.V., Logan, J.A., Higurashi, A., Nakajima, T. (2002). Tropospheric aerosol optical thickness from the GOCART model and comparisons with satellite and sun photometer measurements. J. Atmos. Sci. 59, 461-483. https://doi.org/10.1175/1520-0469(2002)059<0461:TAOTFT>2.0.CO;2

Dong, K., Sun, R., Hochman, G., Li, H. (2018). Energy intensity and energy conservation potential in China: A regional comparison perspective. Energy 155, 782-795. https://doi.org/10.1016/j.e nergy.2018.05.053

Duncan, B.N., Lamsal, L.N., Thompson, A.M., Yoshida, Y., Lu, Z., Streets, D.G., Hurwitz, M.M., Pickering, K.E. (2016). A space-based, high-resolution view of notable changes in urban $\mathrm{NO}_{\mathrm{x}}$ pollution around the world (2005-2014). J. Geophys. Res. 121, 976-996. https://doi.org/10.10 02/2015jd024121

Gelaro, R., McCarty, W., Suárez, M.J., Todling, R., Molod, A., Takacs, L., Randles, C.A., Darmenov, A., Bosilovich, M.G., Reichle, R., Wargan, K., Coy, L., Cullather, R., Draper, C., Akella, S., Buchard, V., Conaty, A., da Silva, A.M., Gu, W., Kim, G.K., et al. (2017). The Modern-Era Retrospective Analysis for Research and Applications, Version 2 (MERRA-2). J. Clim. 30, 5419-5454. https://doi.org/10.1175/JCLI-D-16-0758.1

Hasan, S., Shi, W., Zhu, X., Abbas, S. (2019). Monitoring of land use/land cover and socioeconomic changes in south China over the last three decades using landsat and nighttime light data. Remote Sens. 11, 1685. https://doi.org/10.3390/rs11141658

He, G., Pan, Y., Tanaka, T. (2020). The short-term impacts of COVID-19 lockdown on urban air pollution in China. Nat. Sustainability 3, 1005-1011. https://doi.org/10.1038/s41893-020-0581-y

Huang, K., Zhang, X., Lin, Y. (2015). The “APEC Blue” phenomenon: Regional emission control effects observed from space. Atmos.c Res. 164-165, 65-75. https://doi.org/10.1016/j.atmosre s.2015.04.018 
Huang, L., Lin, W., Li, F., Wang, Y., Jiang, B. (2019). Climate impacts of the biomass burning in indochina on atmospheric conditions over Southern China. Aerosol Air Qual. Res. 9, 2707-2720. https://doi.org/10.4209/aaqr.2019.01.0028

Jaffe, L.S. (1968). Ambient carbon monoxide and its fate in the atmosphere. J. Air Pollut. Control Assoc. 18, 534-540. https://doi.org/10.1080/00022470.1968.10469168

Khatri, P., Ishizaka, Y. (2007). Effects of Continentally polluted airmass on aerosol optical properties over the East China Sea. J. Meteorolog. Soc. Jpn. 85, 47-68. https://doi.org/10.2151/ jmsj.85.47

Khatri, P., Takamura, T., Shimizu, A., Sugimoto, N. (2010). Spectral dependency of aerosol lightabsorption over the East China Sea region. Sola 6, 1-4. https://doi.org/10.2151/sola.2010-001

Khatri, P., Takamura, T., Shimizu, A., Sugimoto, N. (2014). Observation of low single scattering albedo of aerosols in the downwind of the East Asian desert and urban areas during the inflow of dust aerosols. J. Geophys. Res. 119, 787-802. https://doi.org/10.1002/2013jd019961

Landgraf, J., aan de Brugh, J., Scheepmaker, R., Borsdorff, T., Hu, H., Houweling, S., Butz, A., Aben, I., Hasekamp, O. (2016). Carbon monoxide total column retrievals from TROPOMI shortwave infrared measurements. Atmos. Meas. Tech. 9, 4955-4975. https://doi.org/10.5194/amt-94955-2016

Levy, R.C., Mattoo, S., Munchak, L.A., Remer, L.A., Sayer, A.M., Patadia, F., Hsu, N.C. (2013). The Collection 6 MODIS aerosol products over land and ocean. Atmos. Meas. Tech. 6, 2989-3034. https://doi.org/10.5194/amt-6-2989-2013

Li, M., Zhang, Q., Kurokawa, J.-i., Woo, J.H., He, K., Lu, Z., Ohara, T., Song, Y., Streets, D.G., Carmichael, G.R., Cheng, Y., Hong, C., Huo, H., Jiang, X., Kang, S., Liu, F., Su, H., Zheng, B. (2017). MIX: a mosaic Asian anthropogenic emission inventory under the international collaboration framework of the MICS-Asia and HTAP. Atmos. Chem. Phys. 17, 935-963. https://doi.org/10.51 94/acp-17-935-2017

Li, X., Hussain, S.A., Sobri, S., Md Said, M.S. (2021). Overviewing the air quality models on air pollution in Sichuan Basin, China. Chemosphere 271, 129502. https://doi.org/10.1016/j.chemo sphere.2020.129502

Li, X., Zhao, L., Li, D., Xu, H. (2018). Mapping urban extent using Luojia 1-01 nighttime light imagery. Sensors 18, 3665. https://doi.org/10.3390/s18113665

Liang, L., Engling, G., Cheng, Y., Zhang, X., Sun, J., Xu, W., Liu, C., Zhang, G., Xu, H., Liu, X., Ma, Q. (2019). Influence of high relative humidity on secondary organic carbon: Observations at a background site in East China. J. Meteorolog. Res. 33, 905-913. https://doi.org/10.1007/s1335 1-019-8202-2

Liu, F., Beirle, S., Zhang, Q., Dörner, S., He, K., Wagner, T. (2016). NOx lifetimes and emissions of cities and power plants in polluted background estimated by satellite observations. Atmos. Chem. Phys. 16, 5283-5298. https://doi.org/10.5194/acp-16-5283-2016

Ma, T. (2018). An estimate of the pixel-level connection between visible infrared imaging radiometer suite day/night band (VIIRS DNB) nighttime lights and land features across China. Remote Sens. 10, 723. https://doi.org/10.3390/rs10050723

Molod, A., Takacs, L., Suarez, M., Bacmeister, J. (2015). Development of the GEOS-5 atmospheric general circulation model: Evolution from MERRA to MERRA2. Geosci. Model Dev. 8, 13391356. https://doi.org/10.5194/gmd-8-1339-2015

Omidvarborna, H., Kumar, A., Kim, D.S. (2015). NOx emissions from low-temperature combustion of biodiesel made of various feedstocks and blends. Fuel Process. Technol. 140, 113-118. https://doi.org/10.1016/j.fuproc.2015.08.031

Penna, B., Herdies, D., Costa, S. (2018). Estimates of direct radiative forcing due to aerosols from the MERRA-2 reanalysis over the Amazon region. Atmos. Chem. Phys. Discuss. https://doi.org/ 10.5194/acp-2018-355

Randles, C.A., Da Silva, A.M., Buchard, V., Colarco, P.R., Darmenov, A., Govindaraju, R., Smirnov, A., Holben, B., Ferrare, R., Hair, J., Shinozuka, Y., Flynn, C.J. (2017). The MERRA-2 aerosol reanalysis, 1980 onward, Part I: System description and data assimilation evaluation. J. Clim. 30, 6823-6850. https://doi.org/10.1175/JCLI-D-16-0609.1

Remer, L.A., Mattoo, S., Levy, R.C., Munchak, L.A. (2013). MODIS 3 km aerosol product: Algorithm and global perspective. Atmos. Meas. Tech. 6, 1829-1844. https://doi.org/10.5194/amt-61829-2013 
Román, M.O., Wang, Z., Sun, Q., Kalb, V., Miller, S.D., Molthan, A., Schultz, L., Bell, J., Stokes, E.C., Pandey, B., Seto, K.C., Hall, D., Oda, T., Wolfe, R.E., Lin, G., Golpayegani, N., Devadiga, S., Davidson, C., Sarkar, S., Praderas, C., et al. (2018). NASA's Black Marble nighttime lights product suite. Remote Sens. Environ. 210, 113-143. https://doi.org/10.1016/j.rse.2018.03.017

Tie, X., Huang, R.J., Cao, J., Zhang, Q., Cheng, Y., Su, H., Chang, D., Poschl, U., Hoffmann, T., Dusek, U., Li, G., Worsnop, D.R., O'Dowd, C.D. (2017). Severe Pollution in China amplified by atmospheric moisture. Sci. Rep. 7, 15760. https://doi.org/10.1038/s41598-017-15909-1

van Geffen, J., Boersma, K.F., Eskes, H., Sneep, M., ter Linden, M., Zara, M., Veefkind, J.P. (2020). S5P TROPOMI $\mathrm{NO}_{2}$ slant column retrieval: method, stability, uncertainties and comparisons with OMI. Atmos. Meas. Tech. 13, 1315-1335. https://doi.org/10.5194/amt-13-1315-2020

Veefkind, J.P., Aben, I., McMullan, K., Förster, H., de Vries, J., Otter, G., Claas, J., Eskes, H.J., de Haan, J.F., Kleipool, Q., van Weele, M., Hasekamp, O., Hoogeveen, R., Landgraf, J., Snel, R., Tol, P., Ingmann, P., Voors, R., Kruizinga, B., Vink, R., et al. (2012). TROPOMI on the ESA Sentinel-5 Precursor: A GMES mission for global observations of the atmospheric composition for climate, air quality and ozone layer applications. Remote Sens. Environ. 120, 70-83. https://doi.org/10. 1016/j.rse.2011.09.027

Wang, S., Zhao, M., Xing, J., Wu, Y., Zhou, Y., Lei, Y., He, K., Fu, L., Hao, J. (2010). Quantifying the air pollutants emission reduction during the 2008 Olympic Games in Beijing. Environ. Sci. Technol. 44, 2490-2496. https://doi.org/10.1021/es9028167

Wang, Y., Khalizov, A., Levy, M., Zhang, R. (2013). New Directions: Light absorbing aerosols and their atmospheric impacts. Atmos. Environ. 81, 713-715. https://doi.org/10.1016/j.atmosenv. 2013.09.034

Wang, Y., Ma, P.-L., Jiang, J.H., Su, H., Rasch, P.J. (2016). Toward reconciling the influence of atmospheric aerosols and greenhouse gases on light precipitation changes in Eastern China. J. Geophys. Res. 121, 5878-5887. https://doi.org/10.1002/2016jd024845

Wang, Z., Liu, D., Wang, Z., Wang, Y., Khatri, P., Zhou, J., Takamura, T., Shi, G. (2014). Seasonal characteristics of aerosol optical properties at the SKYNET Hefei site $\left(31.90^{\circ} \mathrm{N}, 117.17^{\circ} \mathrm{E}\right)$ from 2007 to 2013. J. Geophys. Res. 119, 6128-6139. https://doi.org/10.1002/2014jd021500

Wang, Z., Liu, D., Wang, Y., Wang, Z., Shi, G. (2015). Diurnal aerosol variations do affect daily averaged radiative forcing under heavy aerosol loading observed in Hefei, China. Atmos. Meas. Tech. 8, 2901-2907. https://doi.org/10.5194/amt-8-2901-2015

Xiao, Q., Ma, Z., Li, S., Liu, Y. (2015). The impact of winter heating on air pollution in China. PLoS One 10, e0117311. https://doi.org/10.1371/journal.pone.0117311

Yan, L. (2020). Legislation of air pollution control in China. IOP Conf. Ser.: Earth Environ. Sci. 512, 012029. https://doi.org/10.1088/1755-1315/512/1/012029

Zhang, Q., Zheng, Y., Tong, D., Shao, M., Wang, S., Zhang, Y., Xu, X., Wang, J., He, H., Liu, W., Ding, Y., Lei, Y., Li, J., Wang, Z., Zhang, X., Wang, Y., Cheng, J., Liu, Y., Shi, Q., Yan, L., et al. (2019). Drivers of improved PM2.5 air quality in China from 2013 to 2017. PNAS 116, 24463-24469. https://doi.org/10.1073/pnas.1907956116

Zhang, W., Lu, Z., Xu, Y., Wang, C., Gu, Y., Xu, H., Streets, D.G. (2018). Black carbon emissions from biomass and coal in rural China. Atmos. Environ. 176, 158-170. https://doi.org/10.1016/j. atmosenv.2017.12.029

Zhao, Y., Nielsen, C.P., McElroy, M.B., Zhang, L., Zhang, J. (2012). CO emissions in China: Uncertainties and implications of improved energy efficiency and emission control. Atmos. Environ. 49, 103-113. https://doi.org/10.1016/j.atmosenv.2011.12.015

Zheng, B., Tong, D., Li, M., Liu, F., Hong, C., Geng, G., Li, H., Li, X., Peng, L., Qi, J., Yan, L., Zhang, Y., Zhao, H., Zheng, Y., He, K., Zhang, Q. (2018). Trends in China's anthropogenic emissions since 2010 as the consequence of clean air actions. Atmos. Chem. Phys. 18, 14095-14111. https://doi.org/10.5194/acp-18-14095-2018

Zhou, B., Wang, Q., Zhou, Q., Zhang, Z., Wang, G., Fang, N., Li, M., Cao, J. (2018). Seasonal characteristics of black carbon aerosol and its potential source regions in Baoji, China. Aerosol Air Qual. Res. 18, 397-406. https://doi.org/10.4209/aaqr.2017.02.0070

Zhou, W.Z. (2020). Emergency Response Strategies for Urban Traffic in Stages of Public Health Security Incidents-written symposium on 2020 New Coronavirus Pneumonia. City Planning Review. http://kns.cnki.net/kcms/detail/11.2378.TU.20200214.1035.002.html

Zhu, X., Tang, G., Guo, J., Hu, B., Song, T., Wang, L., Xin, J., Gao, W., Münkel, C., Schäfer, K., Li, X., 
ORIGINAL RESEARCH

Wang, Y. (2018). Mixing layer height on the North China Plain and meteorological evidence of serious air pollution in southern Hebei. Atmos. Chem. Phys. 18, 4897-4910. https://doi.org/10. 5194/acp-18-4897-2018 